DOI: https://doi.org/10.47405/mjssh.v6i11.1164

\begin{tabular}{|c|c|}
\hline 4 & Malaysian Journal of Social Sciences and Humanities (MJSSH) \\
\hline $\begin{array}{l}\text { Malaysian Juoural of } \\
\text { Social ccciecces and }\end{array}$ & Volume 6, Issue 11, November 2021 \\
\hline (MJ-sSH) & e-ISSN : 2504-8562 \\
\hline & $\begin{array}{l}\text { Journal home page: } \\
\text { www.msocialsciences.com }\end{array}$ \\
\hline
\end{tabular}

\title{
Effects of Social Media on the Interpersonal Relationship among the Married Couples: A Study on a Selected Neighborhood (or Wards) of Dhaka City in Bangladesh
}

\author{
Abu Zihad', Nazmun Nahar Chaitee' ${ }^{2}$, Sahana Rahman ${ }^{2}$ \\ 1Department of Social Work, Open School, Bangladesh Open University, Gazipur-1705, Bangladesh \\ 2Department of Educational Administration, Department of Bangla Noakhali Science and Technology University, \\ Noakhali-3814, Bangladesh
}

Correspondence: Sahana Rahman (sahanarahman37@gmail.com)

\begin{abstract}
It is clearly shown that at present social media plays a vital role in our daily life and the progression in the internet in current years have made new way available to education, health service, business, transportation etc. However, in recent years many sociologists, advocates, educators, psychologists and policy makers have expressed concerns regarding the existing negative impact of social media usage. Some studies have indicated that social media use may be led to negative interpersonal relationship, including infidelity, divorce, disrespect, detachment which often occurs suicide, increases loneliness. Other studies have found evidence for harm what have indicated that social media use may be not so beneficial for some individuals especially in married life. The research was conducted on the neighborhood of Dhaka city with regards to the effects of social media on the interpersonal relationships of married couples. The report identifies the rationale of the research by drawing from popular literature which claims that social media has detrimental effects on quality of marriage. Then relevant literature is reviewed including both national and international researches with regards to the findings regarding effects of social media usage and marriage quality. Usually the usage of Internet among couples was negatively associated with marital satisfaction and commitment of both partners. At the end of the paper, the author discusses the results, along with implications, limitations and recommended future research directions with regards to the acquired information.
\end{abstract}

Keywords: social media, married couples, interpersonal relationship, effect

\section{Introduction}

Dhaka is the capital of Bangladesh and most people come here with aspirations of a better life due to the better access to technology and wider opportunities. Along with these facilities, modern technology has introduced to us with various barriers that has been affecting our family and social life (Valenzuela, Halpern, \& Katz, 2014). Popular studies have shown that individuals with mental instability, depression are increasing because of using too much mobile devices, for instance smartphones (Firth et al., 2015; Glick et al., 2016; Torous et al., 2014). Social media has been reportedly been one of the major causes behind the conflict of relationship. The impact of social networking sites in Bangladesh and found that social networking sites can result in mischievous behavior for people in relationships which could lead them to engage in alleged romantic relationships 
with more than one individual. This induces jealousy, distrust, and partner surveillance tendencies (Faruq et al., 2017). Bangladesh is one of the nations in the world where family bonding and loyalty are taken significantly. However, unfortunately we are slowly moving away from the family values of continuing married life in our country. Divorce cases are turning out very often at this time which is not compatible with our religious values and culture. Social media usage is quite high among the inhabitants of Dhaka (House, 2017). According to Prothom Alo reported dated 22nd December 2020, in just five months from June to October 2020, the rate of divorce has increased dramatically During this time there were 39 divorces daily. Divorce rates are towering among couples. In the five months of this year 5970 divorces have been taken place in Dhaka. Divorce has expanded by 29.78 percent in the first 5 months of this year. Divorced partners used social media in ways which rise significant amount of suspicion. Some the respondents stated that their former partners used social network secretly while blocking their partners. Others stated that their former partners hid their real identity on social media and sent messages to people of the opposite sex. The former partners were also found to hide their marital status from social media platforms (Aydin et al., 2018; Cravens et al., 2013). It was also found that if social media was used for maintaining connection with people other than family or friends while excluding respective partners, the rate off dissatisfaction was high among spouses (Whiteside et al., 2018). The research also suggested that excessive social media usage corrupted family relations and increased depression and insecurity for respective partners (Haris et al., 2014).

The fight, unfaithfulness and jealousy that commences from social media use is connected with relationship conflict, breakups, and even divorce (Clayton, 2014; Clayton, Nagurney, \& Smith, 2013; Cravens, Leckie, \& Whiting, 2013; Fox, Osborn, \& Warber, 2014; Ridgway \& Clayton, 2016; Valenzuela, Halpern, \& Katz, 2014). Based on popular literature, social media usage has been reportedly responsible for reducing quality of marriage between married individuals and interfere with relationships, mental illness and demolish relationship satisfaction (McDaniel \& Coyne, 2016; Roberts \& David, 2016). Due to the massive use of social media, the social ceremonies were found to have become merely ornamental for most cases. The research also stated that social media inadvertently made people less social which affected the bonding between individuals. Social Network sites (SNS) addiction lead to several problems relating to social and psychological aspects which results in reduced commitment in relationships. On the other hand, this low commitment also influences people to develop interest in others as partners. In addition, it was also found that the younger couples were more prone to SNS addiction in comparison to older couples. So, the chances of SNS jealousy and infidelity was higher in younger couples than in older ones (Abbasi, 2019). Emmanuel (2014) found that about $39 \%$ of the respondents visited social media regularly. All of the respondents were either married or in a courtship. Only about $35 \%$ of the respondents share the pictures of their partners and themselves as couples and about $12 \%$ is open about their relationship status. (Parvez et al., 2019) conducted a study on the teenagers of Bagerhat, a district in Bangladesh, and found that about $54 \%$ of the respondents spend about 2 hours every day on social media. About $88 \%$ of them access these SNS through mobile phones. And reportedly, $80 \%$ of the individuals used these SNS for chatting purposes. and $45 \%$ of the respondents admitted that chatting was the most entertaining aspect of using social media. $85.7 \%$ of the respondents admitted that using SNS improved the relationship with friends. It was also reported that it developed the relationship with family as well, because they were able to spend more time with them through social media. But $77 \%$ of the respondents also stated that social media wastes valuable time. lastly, it was found that $88 \%$ of the respondents increased expenditure due to the purchase of internet packages.

This research aims to identify the effect of social media on interpersonal relationships of married couples selected neighborhood of Dhaka city. In order to do this the research will explore the perception, frequency and type of usage associated with social media and will also explore the factors that affect interpersonal relationship of married couples relating to social media. Ullah (2015) suggested that almost all of the public uprisings and public protests after 2010 were fueled by Facebook. This denotes a significant involvement of the youth on social network platforms and whatever is posted of Facebook, if resonant with the perception of the viewer or the audience, will be circulated at a fast pace. This indicates that Facebook is a significant influencer among the youth of Bangladesh. 
This research will help to determine the extent to which a portion of the adult population is reliant on social media. It will provide insight on behavior that they exhibit in regards to social media usage. And when the findings will be cross referenced with the quality of relationship that they exhibit in their married life then the degree to which social media affects interpersonal relationship scan be identified (Al Mamun \& Griffiths, 2019). This will broaden the scope towards optimizing lifestyle choices that help to develop interpersonal relationships. Lastly, the research will broaden the scope for future researches which intend to explore behavioral dynamics of married people in Bangladesh.

\section{Rationale of the Study}

At present almost everyone has gone through financial, social and family stress due to global issues like usage of social media excessively. It has also increased marital dissatisfaction among the people. Extra marital affairs are exacerbating marital strife. Divorce is on the rise due to family quarrels. The incidence of divorce in 2019 has increased by 17 percent compared to 2018. (Sourav, 2019) also added that from 2012-2019 more than 69,000 divorces took place in Dhaka, as per the statistics of Dhaka City Corporations. Moreover, about 730 divorce applications are being filed every month in North and South City corporations of Dhaka. When observed from a broader perspective, these cases are not only affecting the divorcees, but also their family members. One of the main causes behind these divorces was extra marital affairs. Other causes included addiction, domestic abuse, lack of attention, maladjustment with family values, suspicion and increased awareness on regards to psychological oppression (Ghasemi \& Saroukhani, 2013).

According to (Valenzuela et al., 2014), usage of social media decreases marriage stability. Moreover, $20 \%$ annual enrollments in Facebook resulted in 2.18\%- 4.32\% increase in divorce rates. The reasons behind such increase in divorce rates was found to be too much time spent on social media, tendency to be suspicions and snooping around with spouses' social media information and jealousy against social media acquaintances. In addition, $10 \%$ of the adults in relationships admitted to have hidden posts and texts from their significant other and $8 \%$ had secret accounts.

It is evident that social media has significant influence on reducing quality of marriage through instigating extra marital affairs, inducing distrust between spouses and by increasing jealousy and suspicion between them (Sharar, 2018). It can be considered as one of the drawbacks of modern technology that might turn out to be quite significant if not addressed with appropriate measures. Hence, this study aims to identify the impact of social media on interpersonal relationships of married couples. The findings will help to determine the core factors that affect the quality of such relationships which will consequently help to determine appropriate measures that could minimize the detrimental effects and hopefully reduce the divorce rates among the inhabitants of Bangladesh. This will help to maintain social tranquility and will also be a positive step towards sustaining good mental health of children of married couples.

\section{Objectives of the study:}

The main aim of this research is to identify the effect of social media on married couples selected neighborhood in Dhaka city. Some specific objectives have been formulated, the achievement of which will lead to the completion of the research aim. These objectives are provided in the following segment.

i. To determine how social media is perceived and used among married couples.

ii. To analyze the positive and negative effects of social media on psychology, economy and relationship of married couples.

iii. To point out how could minimize the detrimental effects of social media (on married couples) and facilitate the benefits for betterment of relationships. 


\section{Methodology}

This study was quantitative in nature. The researchers have undertaken social survey method mainly. The social survey method has been assisted to acquire necessary information of this research. A descriptive triangulation approach is used to analyze the data.

\section{Area of the study}

The area of the study covers all the areas of Lalbag and New Market which is located under Dhaka South City corporation and the word no is 61 and 52. The study area has been selected through purposive sampling procedure for the purpose of convenient data collection.

\section{Sample selection and sample size}

All the married couples within the research area were the population of the study and every married male and female have been treated as the sample of this study. Each respondent irrespective of color, caste., age, profession and religion was considered as a unit of analysis. The sample size was 200 married couples living in the research area. The respondents who are currently married or have been married at some point of their lives and have been using social media platforms have selected for this research.

\section{Data Collection and Sampling}

Data have been collected from both primary and secondary sources to collect primary data adopt nonprobability sampling has been used for purposive sampling procedure for collecting data. For this purpose, a semi structured interview schedule (open and close ended) was prepared. Secondary data have been gathered from various relevant research reports, journals, books, websites, as well as from record and documents of relevant agencies. Moreover, observation technique has been applied for data collection.

\section{Data Analysis}

After completion of field inquiry the collected data have been edited to ensure accuracy of information. The data have been analyzed by using MS Excel and SPSS software.

\section{Period of Data collection}

Primary data of this research were collected within December 152019 to March 25,2020.

\section{Ethical considerations:}

For the secondary data used in this research, the journals, articles, research papers, newspaper etc. were properly cited and the authors and publishers were given due credit. The information was presented as it is. For the primary data, the respondents were provided with adequate information prior to the data collection phase. They were not forced to provide responses. In addition, the acquired information was not falsified, the data was provided it was acquired.

\section{Findings}

\section{Age group and Gender}

The social media users couples are mostly the age group of $20-40$, about $71 \%$ couple use social media at the age of 20 to 40 . In addition, 51 to above 60 they didn't use social media that much only $11 \%$ had responded that. Result shows that wife are more active in social media than husband, since Majority of husband are earning person in the family it might be a reason for that they don't have much time to spend on social media rather than job or business. 
Figure 1: Age Group of Couples

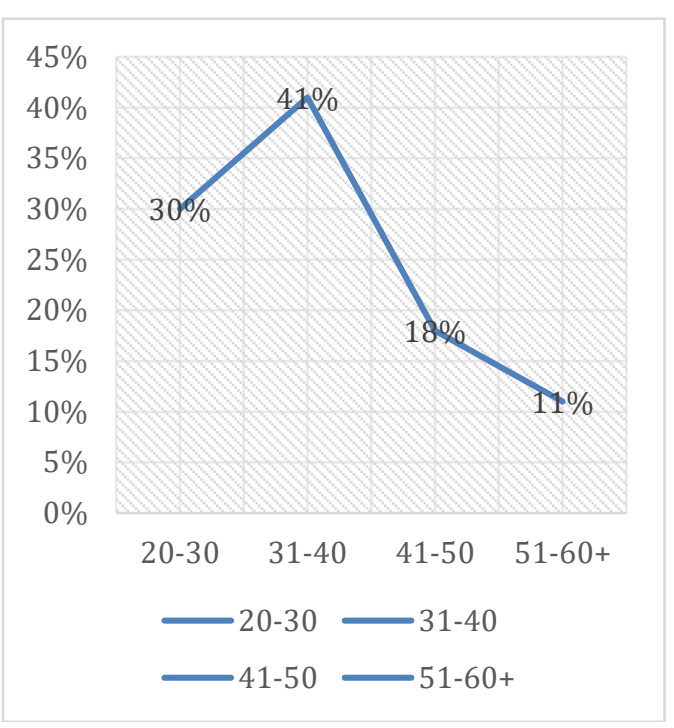

Figure 2: Gender who uses social media more

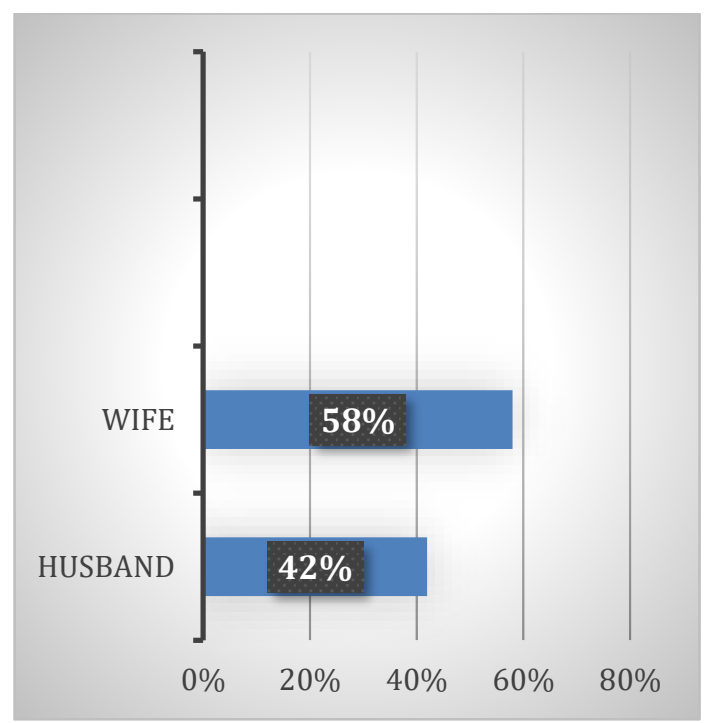

\section{Education and social media usage}

It was found that about 9 out of 10 of the total respondents used social media on a regular basis and about $45 \%$ of these individuals were honors graduates. About $38 \%$ of them had a post graduation degree and mere $12 \%$ had an HSC and $6 \%$ had SSC degree.

Figure 3: Educational qualifications of the respondents

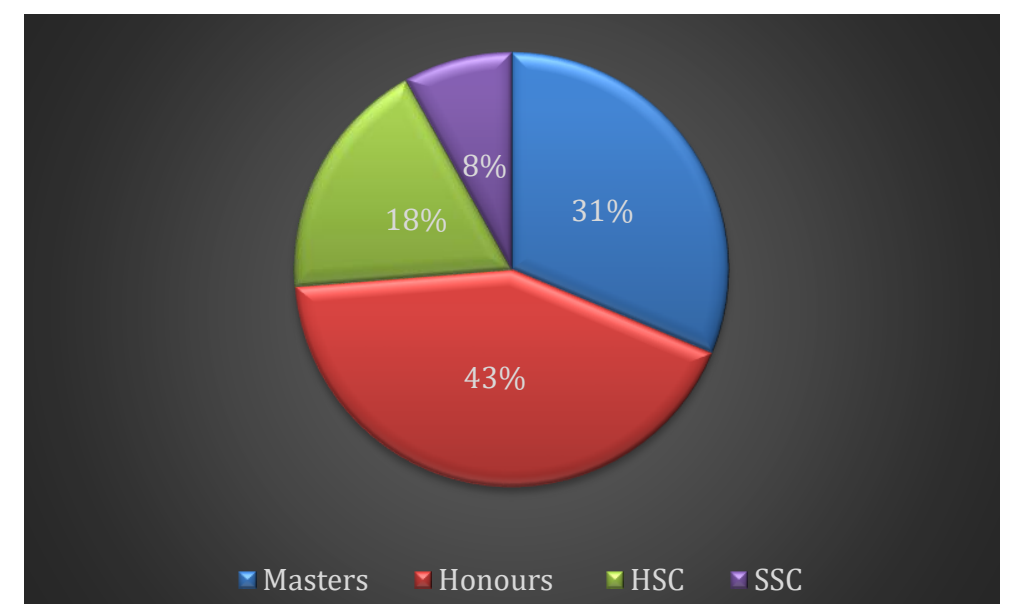

\section{Usage of Social Media}

Around to $34 \%$ of the married couple used only face book. And about 52\% of them used Facebook along with other social media sites like YouTube and whatsApp, about $7 \%$ of them used Facebook along with other social media sites like SKYPE, IMO etc. However, $7 \%$ of them use others social media except Facebook. In a staggering 93\% of the cases, the individuals accessed the internet through their smart phones. Even though around 65\% had access to both laptops and Desktop computers. Accessing the internet through smart phones was most convenient. In addition, all of them were involved in some sort of occupation. Moreover, as majority of the users were accessing the internet or social media platforms through their cell phones, it can be inferred that most individuals using social media had constant access and they were able to maintain a significant degree of privacy as smartphones are generally used by unique users. 
DOI: https://doi.org/10.47405/mjssh.v6i11.1164

Figure 4: Categories of social media used

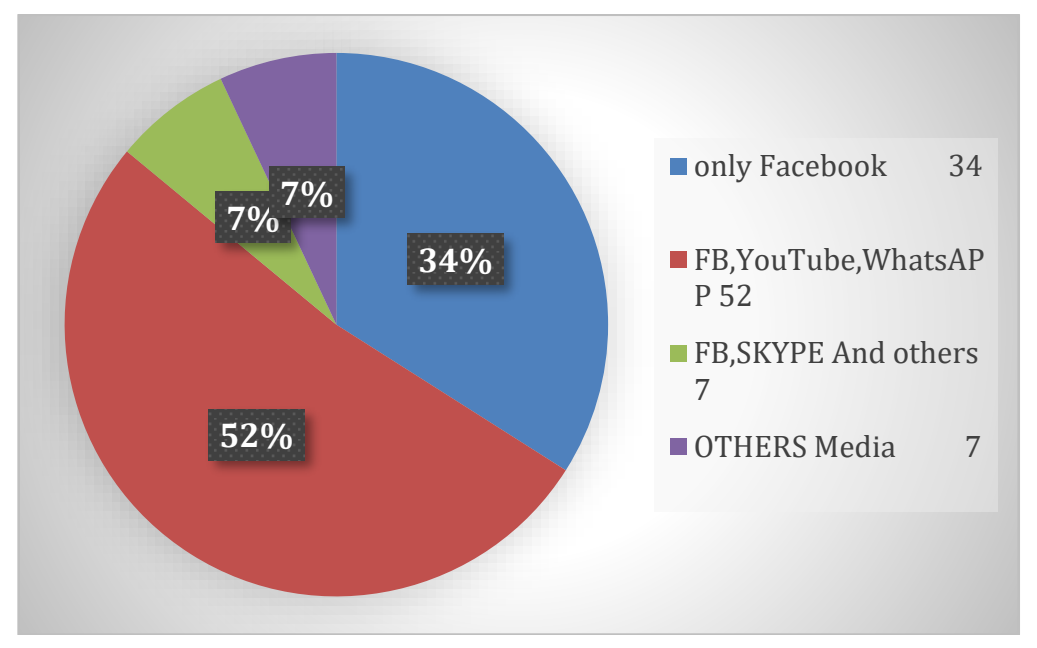

Figure 5: Social media usage (Hours per day)

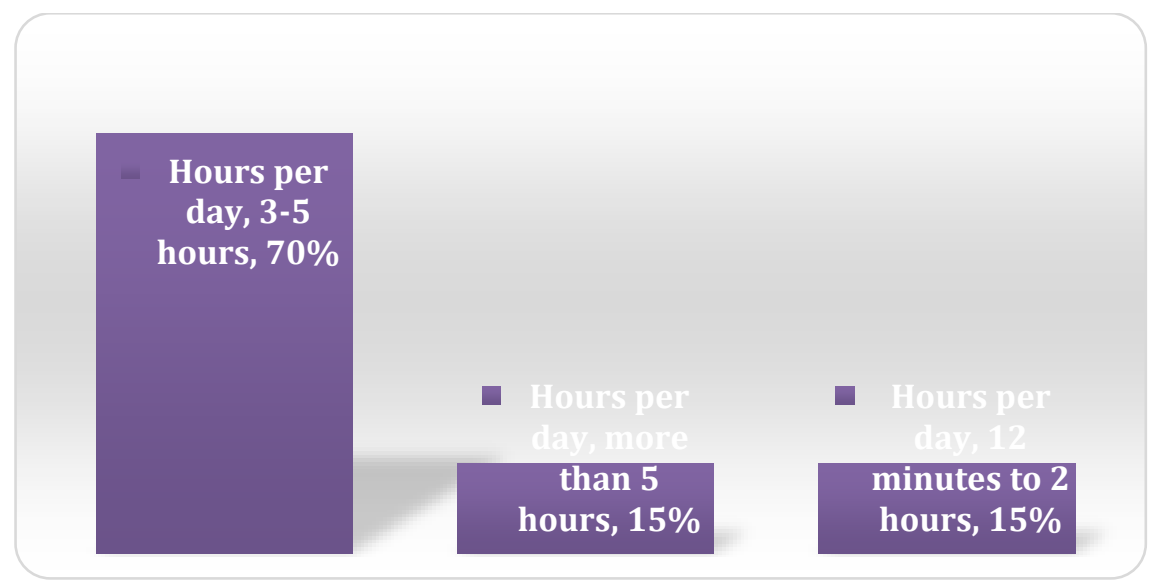

They reported that they spent 3-5 hours everyday. That is about $70 \%$ of the individuals reported that they used Facebook along with other social media platforms 3-5 hours a day. 1.5 individuals out of 10 reported that they use social media more than 5 hours per day and the rest $15 \%$ used social media from 15 minutes to 2 hours per day.

\section{Reasons of using social media}

About $72 \%$ of the married couple reported that they use social media solely for chatting and staying updated about the incidents in their social circle and also uploading photos, checking status of the people in their contacts. It is suggestive of the fact that individuals chatting is one of the most convenient and lucrative form of pass time for majority of the individuals. it is also discrete and anonymous which helps individuals to chat with multiple people at the same time. About $8 \%$ use social media for solely business purposes and $14 \%$ use social media for job and educational purpose. And $6 \%$ use social media for others such as medical services, food service, online shopping etc. 
Figure 6: reasons for using social media

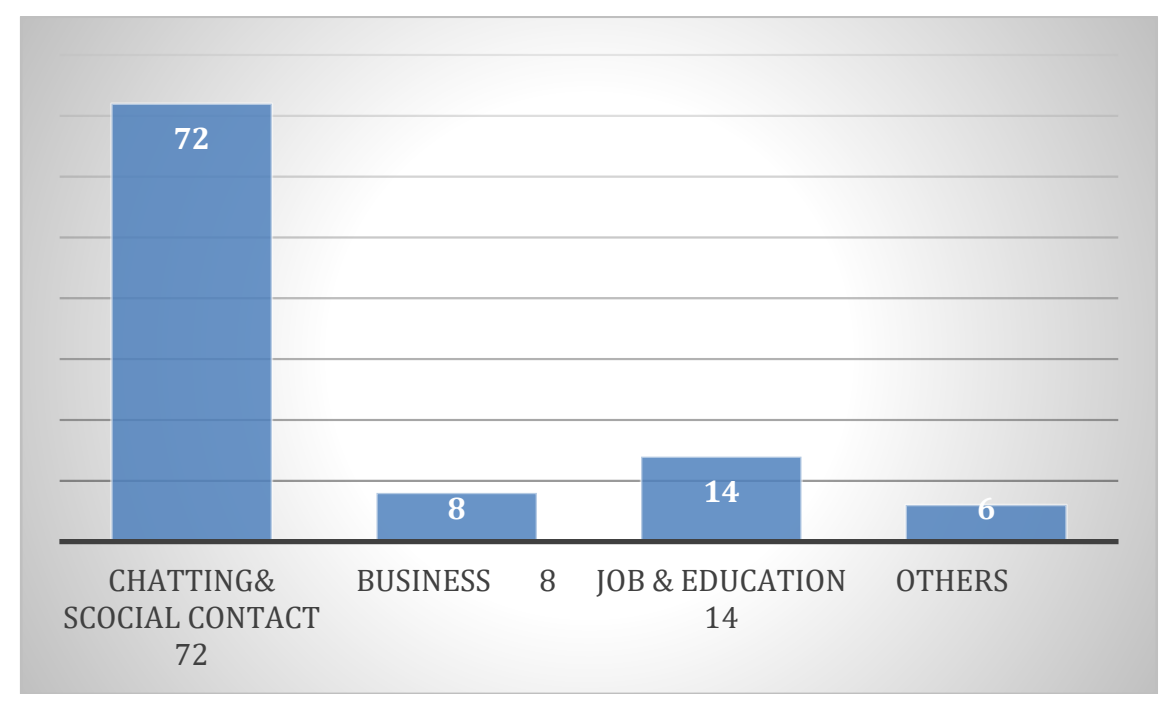

\section{Relationship between social media with couples}

More than $63 \%$ of the married couple reported that avoiding social media was difficult for them as it had become an integral part of their lives and it removed monotony and loneliness but some coupled mentioned social media had used for financial, educational, social purpose etc. About $37 \%$ of the respondents reported that they could avoid social media, for few of them mentioned social media is one kind of wastage of time for them, others said without social could be boring but not possible and the others considered for social media people stay awake at night for browsing contents on social media can be harmful for health so considering this demerit they could avoid social media.

Figure 7: Dependency on social media

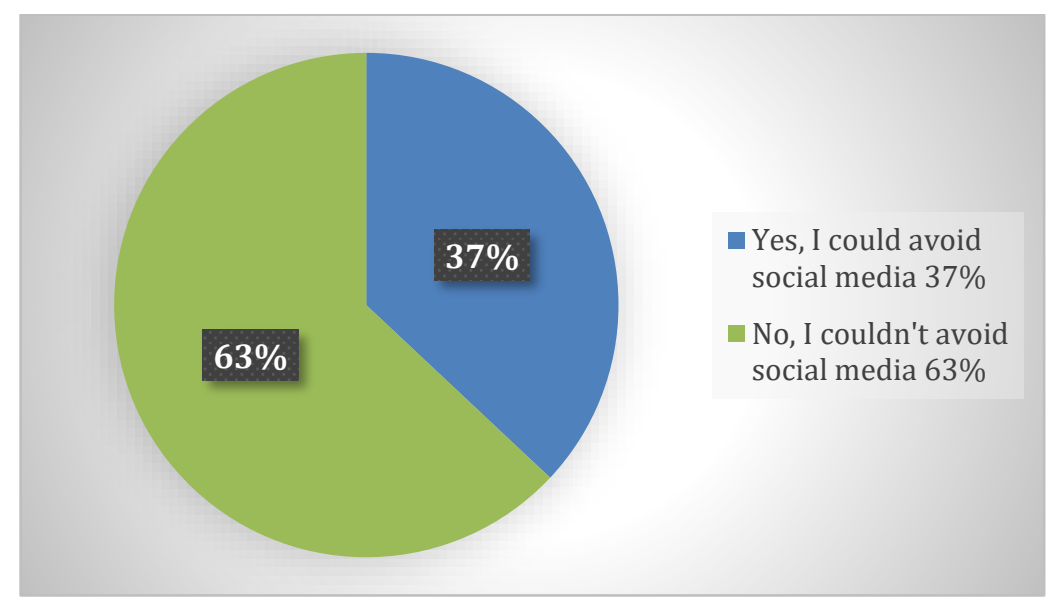

Only about $33 \%$ married couples had their relationship status visible for friends or public willingly, even they felt happy to talk about their spouses. The rest $67 \%$ did not post their relationship status on social media sites or tried to hide it from opposite gender especially. About $33 \%$ of the individuals post content on their social media with their partner or regarding their partner and they didn't have to hide chat list for that reason they hadn't problem to share friend list. However, about $67 \%$ do it rarely and didn't share their chat history and friend list and often they removed chatting from chat list. It is indicative of the fact that most of the individuals want their relationship status to be private because of security reasons or for being able to connect with people without boundaries. 
Figure 8: Honesty about relationship status on social media

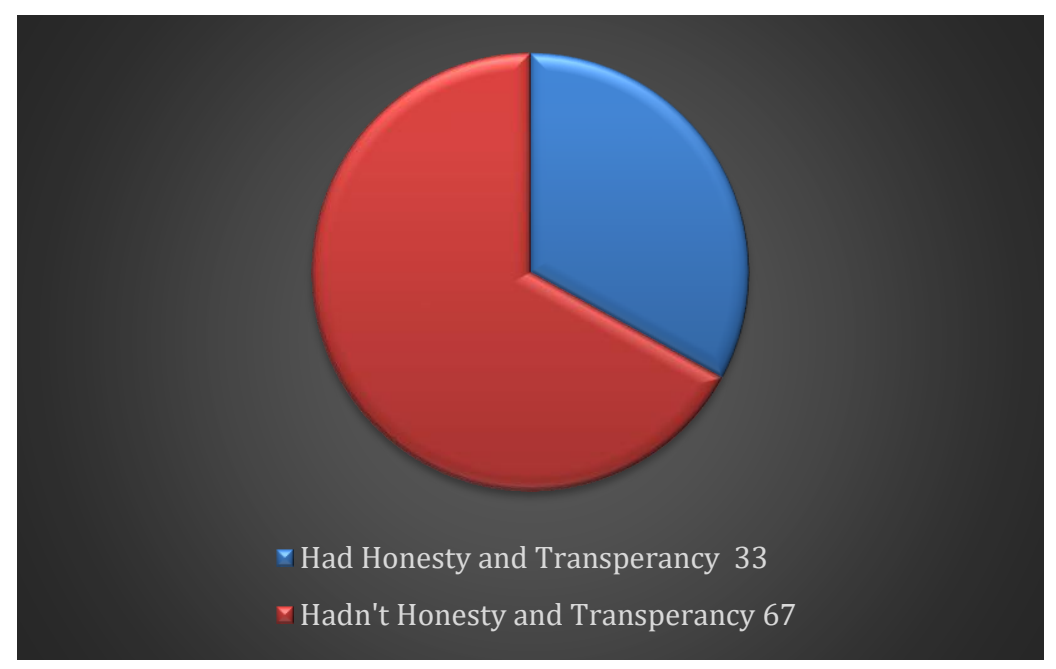

\section{Effects of social media usage on relationships}

About $97 \%$ of the married couple reported that when their respective partners share their photo or a write a post regarding them, they feel empowered and appreciated and only $3 \%$ were not concerned about it. This shows that individuals feel good when their respective partners are open about their relationships. But in most cases, this does not happen which makes them anxious about the loyalty or commitment of their respective partners. It was also found that $88 \%$ of the couple felt jealous when their respective partners were in contact with someone of the opposite gender on social media. Only about $12 \%$ were not jealous. It is indicative of the strong masculine characteristics of the society of Bangladesh. The response of the individuals towards the activities of their respective partners validated this inference. Most of the individuals reported that when acquaintances on social media like and comment on their couple photos, they feel recognized and a sense of security is instilled.

Figure 9: Partner's post and Appreciation

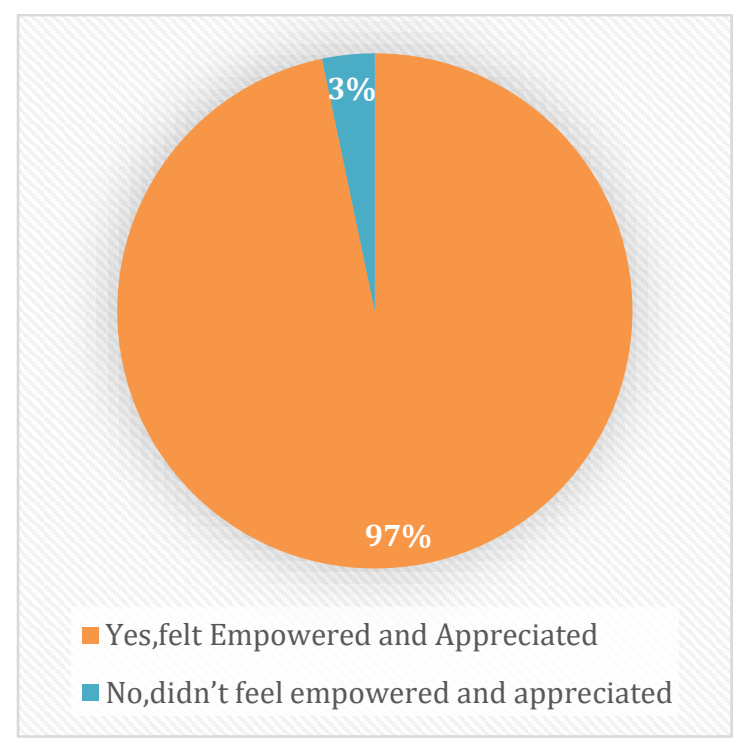

Figure 10: Partner's interaction and Jealousy

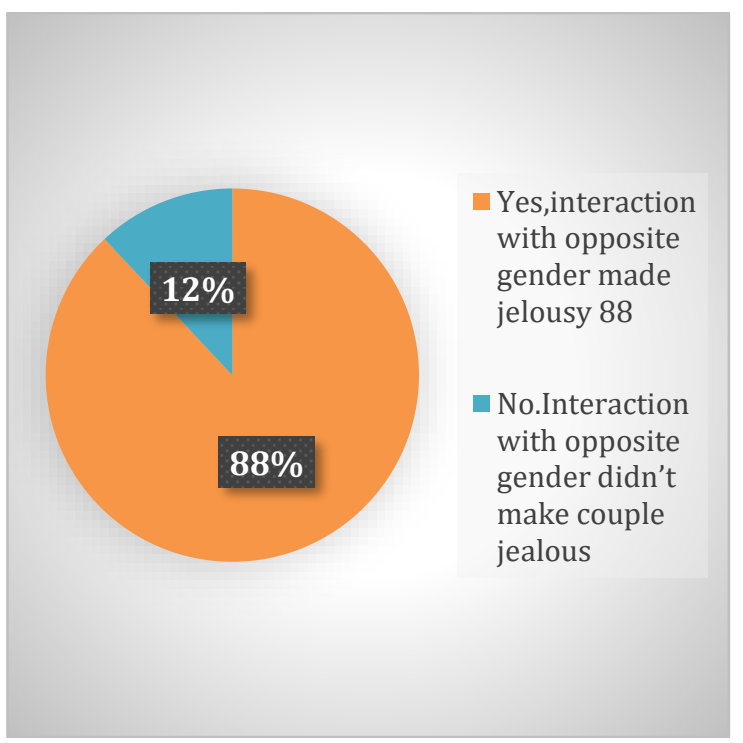

In about $60 \%$ of the cases, the respondents reported that they were spending most of the time with social media rather than with their partner. This can occur due to the immense work pressure experienced by these individuals or the tendency of taking their respective partners for granted. They also admitted that such behavior from their significant other makes them feel unwanted and insecure. More than $6 / 10^{\text {th }}$ of the respondents reported that they enjoy the company of their virtual social circle 
rather than their partner. And about $4 / 10^{\text {th }}$ reported the opposite and $40 \%$ couples enjoyed more time with partners than social media.

Figure 11: Spent time on social media more than with partner

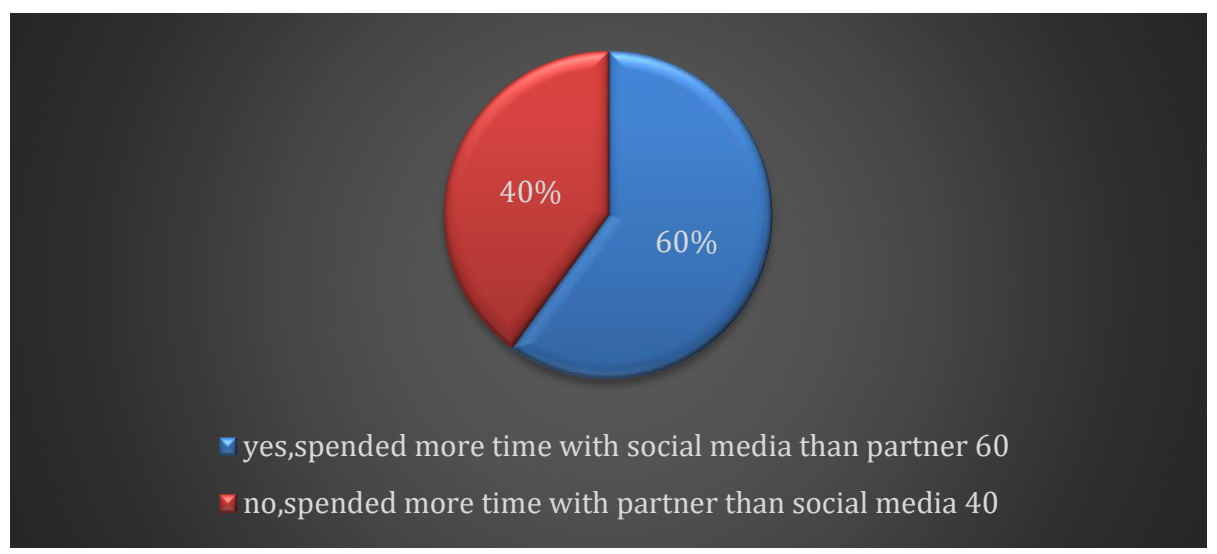

Almost $17 \%$ of the couple had caught their respective partners flirting with other individuals on social media platforms at some point of their relationship. And about $20 \%$ suspect their partner to have extra marital affairs. Moreover, about $21 \%$ of the individuals have fights over social media issues with their respective partners. These individuals who have fights with their respective partners have also reported that they are not getting adequate attention form their partners. This is indicating that when individuals spend more time on social media, their respective partners feel left out and alone. This instigates suspicion and jealousy which in turn gives rise to fights. These fights can develop a sense of bitterness between the individuals which could potentially result in dissolution of marriage. Surprisingly about $42 \%$ couples said they had not faced any problems for using social media though it's quite difficult to trust may be couples felt shy for revealing personal life.

Figure 12: Problems occurred for Social Media

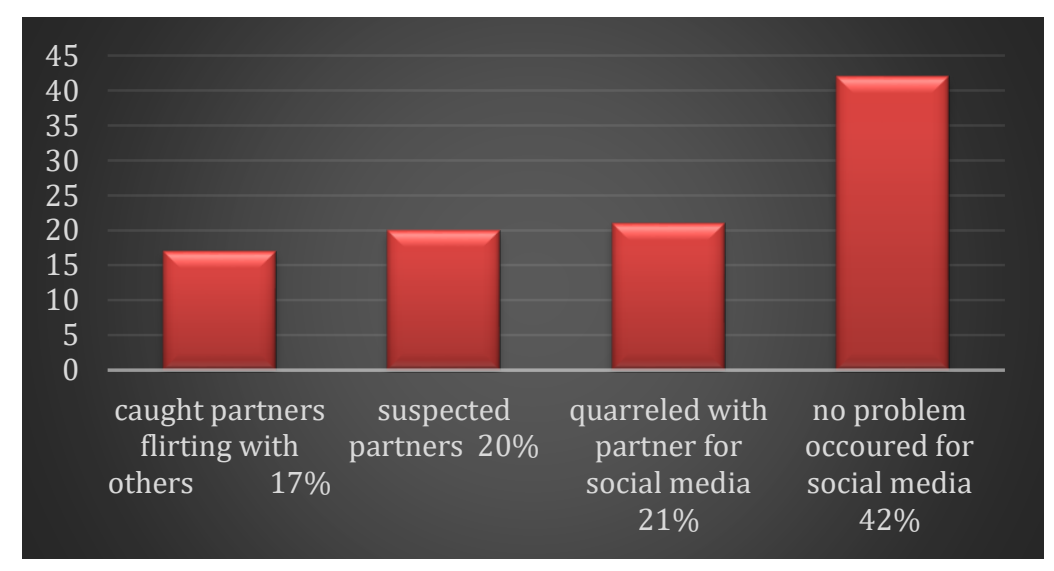

Almost $40 \%$ of the married couple feels that their loyalty is questioned by their partner. They also feel that there is inadequate trust between them. About $80 \%$ of the married couple also have problem sharing their passwords with heir significant other. But 7 out of 10 of the men were inclined towards knowing the password of their respective partners. This indicates that women have more trust on their male partners while men have less trust on their female partners.

Surprisingly only about $12 \%$ of the couple had hidden their social media identities form their respective partners. And more than $61 \%$ has reported that they felt insecure due to social media usage of their partners. So, it can be inferred that hiding social media identity does not affect suspicion. 
Only about 5 out of 100 of the respondents reported that they will stop using social media if that results in a better relationship with their partner. So, it is evident, that social media holds more importance than conjugal peace and tranquility. Moreover, the individuals who are not willing to give up using social media for the sake of their relationship, might have alternatives which might be able to satisfy their social needs which apparently was not being served by the marriage.

Figure 13: Tendency of hiding social media id from partner

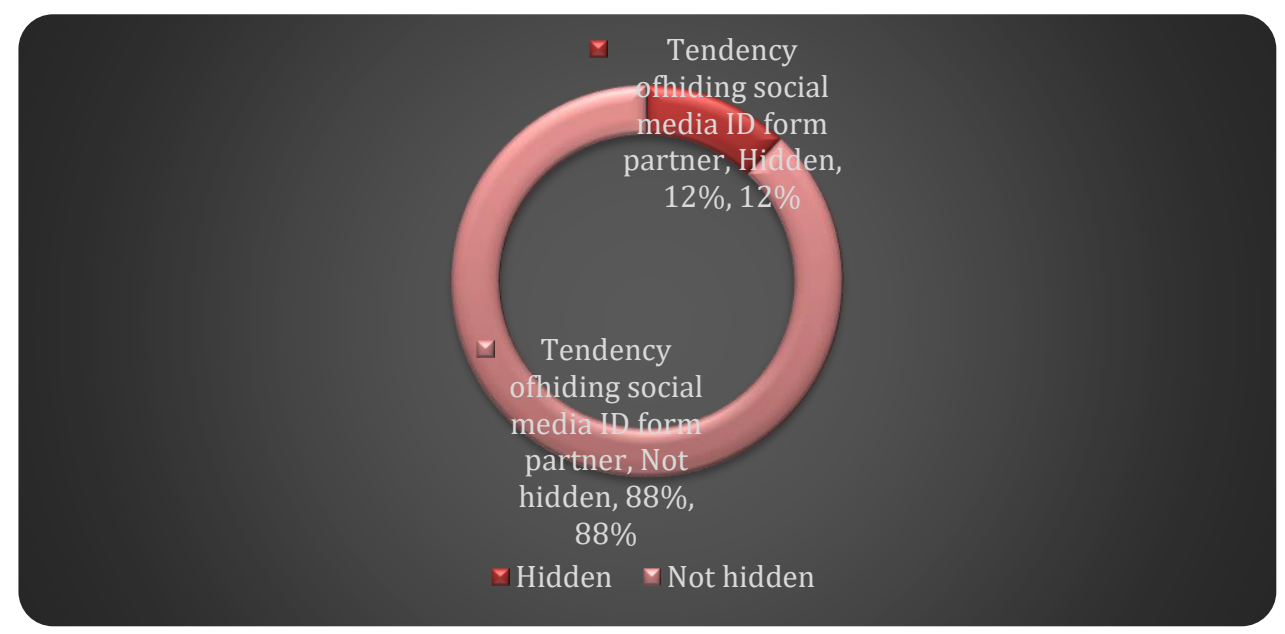

\section{Discussion}

The primary purpose of this study was to determine if a relationship existed between social media usage and how it affects the married couple interpersonal relationships. A social survey was distributed on social media like Facebook. WhatsApp etc. A sample size of 200 married couples completed the survey. The quantitative results were analyzed using SPSS, MS Excel. In this interpretation, we considered the relationship between social media and conjugal life. Social media is now an integral part of daily life, with possible benefits and threat to mental peace as well as relationship but the fact is most of the people ignores it even in our study highly educated person have focused more on social media than the less educated person. Graduated person likes to spend more time in social media and Facebook is the most popular social media not for the single person but also married person. Though majority of people use Facebook along with other social media like YouTube, Skype. Very few people think Facebook is nothing just wastage of time and they have freed themselves from FB.

Shocking part is revealed that people usually use social media without specific reason, almost $70 \%$ people use social media 3-5 hours randomly. However, the productive work is happened occasionally most of the cases people spend time by chatting, gossiping or we can say they take it as a great source of time pass. Even some couples are so on to it that they couldn't quit social media so much dependency on social media and only 37\% couples agreed to avoid it. As previous research has shown that social media use can be ensued relational complexity, conflict and dissatisfaction (Clayton, 2014; Clayton et al., 2013; Cravens et al., 2013; Fox et al., 2014; Ridgway \& Clayton, 2016; Valenzuela et al., 2014) and lower levels of love (Northrup \& Smith, 2016). This paper has found the same almost $67 \%$ couples are not honest about their relationship status and lack of transparency. Moreover, most of the couples are excited to see their partner's acknowledgement and if their partners show love or affection toward them through social media make them motivated and empowered. Another fact is spouses are conscious about partners activity in social media, often they have insecurity and feel jealous on partner's involvement with opposite gender, only $12 \%$ couples do not give much attention on it actually they felt secured with partner.

Shockingly $60 \%$ responded that they enjoyed the time with social media more than partners even virtual friends might be important than family life sometimes which occurred many problems and 
affected married life badly such as fight with partners, extra marital affairs, mistrust has increased immensely.

Almost $88 \%$ responded that they didn't hide social media from partner though most of them didn't agree to share their password with partners. Very few couples only $5 \%$ responded that social media was more importance than conjugal peace and tranquility that's why they could quit social media if the relationship would be better.

Finally analyzing the paper some factors have found: social media users are mostly educated, No other social media is as famous as Facebook, People Idly use social and it kills our valuable time as well as damages family bonding, Social media can cause anxiety and depression, Most of the respondents are dependent on social media especially the age group of 25-35, Social media opens people to diverting their mind and choosing another partner, Social Media is addictive for many, Majority of couples try to maintain their privacy from partners, Social Media can be the reason of relationship's issues.

\section{Conclusion}

In order to instill trust between married individuals, they need to have certain degree of transparency to the point where there is no scope for being suspicious. People should be more active in expressing their feelings for their respective partners so that the sense of insecurity is not sustained. Moreover, married couple should be honest about their relationship status on their social media. This does not only help to be transparent but also develops relationship between them as their relationship is recognized. Married couple should also limit their social media usage and focus more on sustaining the relationships with family. Excessive usage of social media does not only affect health, but also affects relationship between married individuals. in addition, every individual should be willing to give adequate space to their respective partners so that they don't feel suffocated. Feeling suffocated in relationships can often lead to fights and quarrels.

Finally, married couple should be more appreciative of their respective partner's efforts in regards to making the relationships better and should recognize them. If public recognitions are not an option to pursue, the recognition should at least be at a personal level. Being open and talking about issues that are being faced due to social media can also help to mediate issues that might potentially strengthen the bond between married couple.

The research has identified that social media usage has significant effect on interpersonal relationships of married couples if it exceeds a certain acceptable threshold. This threshold is subjective and is not applicable to all cultural contexts. Many issues, identified in this report e.g. jealousy, suspicion, arguments between married individuals etc. have been attributed to the cultural context of Bangladesh. But excessive social media usage and inadequate recognition of the respective partners does affect marriage quality in a detrimental fashion. The research was conducted by utilizing both primary and secondary sources which has repeatedly proven that irresponsible and unnecessary use of social media can be quite harmful for the interpersonal relationships of married couples in the neighborhood of Dhaka city.

This paper has followed general guidelines for a standard article. Nevertheless, research is a complex, complicated and scrutinizing activity based on scientific knowledge and competence. The findings may not be generalized because of the not representative sample, as only those married couples ere included who volunteered to participate. The respondents were not mention their name or sign so that their identities remain unknown to us. Moreover, one of the major challenges of this study was data collection. There is a limited empirical literature on the area of effects of social media on social media usage on interpersonal relationship of married couples especially no article had found in Bangladesh's perspective. Another expected limitation is that the couple might fail to give correct information on the basis of invasion of their privacy. 
As interpersonal relationship is a very personal and sensitive issue in our society, respondents were also confused about their experiences and also confused about their experiences and could not provide an answer that could adequately satisfy the research question. The respondents were busy in their household or official works. They didn't have enough time to participate in the long time for semi structured interview. the study is limited by time and budgetary resources. And as a result the research will have to source for more economic resources and use alternative means. After all, the research was carried out in a new field of knowledge. Besides the limitations it can be a first hand data for the researchers who carry out similar type of investigation in future.

\section{References}

Abbasi, I. S. (2019). Social media addiction in romantic relationships: Does user's age influence vulnerability to social media infidelity?. Personality and Individual Differences, 139, 277-280.

Afroz, S. (2019). The Rise of Divorce in Bangladesh: A Review in the Change of Marriage Dynamics. Social Sciences, 8(5), 261-269.

Al Mamun, M. A., \& Griffiths, M. D. (2019). The association between Facebook addiction and depression: A pilot survey study among Bangladeshi students. Psychiatry research, 271, 628633.

Aydın, B., Sarı, S. V., \&Sahin, M. (2018). The effect of social networking on the divorce process. Universal Journal of Psychology, 6(1), 1-8.

Business Standard. (2018). Divorces on rise among educated couples in Bangladesh: Official data. Retrieved from https://www.business-standard.com/article/pti-stories/divorces-on-rise-amongeducated-couples-in-bangladesh-official-data-118082700887_1.html

Clayton RB. (2014). The Third Wheel: The Impact of Twitter Use on Relationship Infidelity and Divorce. Cyberpsychology, Behavior, and Social Networking, 17(7), 425-430.

Cravens JD, Whiting JB (2014). Clinical Implications of Internet Infidelity: Where Facebook Fits In. The American Journal of Family Therapy, 42(4), 325-339.

Emmanuel A. O. (2014). An Assessment of the Role and Utilization of Facebook As a Social Media in Courtship And Marriage Among Undergraduate Students of Ahmadu Bello University, Zaria, Nigeria.

Faruq, M. O., Rahman, M. M., \&Alam, M. R. (2017). Impact of social networking sites in Bangladesh: Few Possible Solutions. International Journal of Intelligent Systems and Applications, 9(4), 53.

Firth, J., Cotter, J., Torous, J., Bucci, S., Firth, J. A., \& Yung, A. R. (2015). Mobile phone ownership and endorsement of "mHealth" among people with psychosis: a meta-analysis of cross-sectional studies. Schizophrenia Bulletin, 42(2), 448-455.

Fox J, Osborn JL, Warber KM. (2014). Relational dialectics and social networking sites: The role of Facebook in romantic relationship escalation, maintenance, conflict, and dissolution. Computers in Human Behavior, 35, 527-534.

Ghasemi, A., \& Saroukhani, B. (2013). Factors related to divorce in couples applying for uncontested divorce. Social Studies in Iran, 10(39), 69-87.

Glick, G., Druss, B., Pina, J., Lally, C., \& Conde, M. (2016). Use of mobile technology in a community mental health setting. Journal of Telemedicine and Telecare, 22(7), 430-435.

Hand, M. M., Thomas, D., Buboltz, W. C., Deemer, E. D., \& Buyanjargal, M. (2013). Facebook and romantic relationships: Intimacy and couple satisfaction associated with online social network use. Cyberpsychology, Behavior, and Social Networking, 16(1), 8-13.

Haris Farooq, D., Chaudhry, A. G., \& Ahmed, A. (2014) impact of information and communication technologies on traditional wedding and funeral ceremonies in punjab, pakistan.

House, OF. (2017). Freedom on the Net, Bangladesh https://freedomhouse.org/report/freedomnet/2017/manipulating-social-media-undermine-democracy

Luhmann, N. (2012). Theory of society. Stanford, California: Stanford University Press.Parvez, M. S., Rahaman, M. A., Fatema, K., \& Mondal, D. R. (2019). Impact of Social Networking Sites on Interpersonal Relationship among Teenager: A Sociological Analysis in the District of Bagerhat. British J. of Arts and Humanities, 1(5), 14-27. 
McDaniel BT, Coyne SM. (2016). "Technoference": The interference of technology in couple relationships and implications for women's personal and relational well-being. Psychology of Popular Media Culture, 5, 85-98.

Parvez, M. S., Rahaman, M. A., Fatema, K., \& Mondal, D. R. (2019). Impact of Social Networking Sites on Interpersonal Relationship among Teenager: A Sociological Analysis in the District of Bagerhat. British J. of Arts and Humanities, 1(5), 14-27.

Ridgway JL, Clayton RB (2016). Instagram unfiltered: Exploring associations of body image satisfaction, Instagram \#selfie posting, and negative romantic relationship outcomes. Cyberpsychology, Behavior \& Social Networking, 19:2-7.

Roberts JA, David ME. (2016). My life has become a major distraction from my cell phone: Partner phubbing and relationship satisfaction among romantic partners. Computers in Human Behavior, 54, 134-141.

Sharar, R. (2018). Insight into decision of marriage by late teens and early-twenties women in Dhaka middle class: their agency, respectability and role of external factors (Doctoral dissertation, BRAC University).

Sourav, D. (2019). Divorce rate increases in capital Dhaka. Bangladesh Post. Retrieved from https://bangladeshpost.net/posts/divorce-rate-increases-in-capital-dhaka-10990.

Torous, J., Chan, S. R., Tan, S. Y.-M., Behrens, J., Mathew, I., Conrad, E. J., et al. (2014a). Patient smartphone ownership and interest in mobile apps to monitor symptoms of mental health conditions: a survey in four geographically distinct psychiatric clinics. JMIR Mental Health, $1(1)$, e5.

Ullah, M. S. (2015) Social Media and its impact on Bangladesh.

Utz, S., \&Beukeboom, C. J. (2011). The role of social network sites in romantic relationships: Effects on jealousy and relationship happiness. Journal of Computer-Mediated Communication, 16(4), 511-527.

Valenzuela, S., Halpern, D., \& Katz, J. E. (2014). Social network sites, marriage well-being and divorce: Survey and state-level evidence from the United States. Computers in Human Behavior, 36, 94-101.

Whiteside, N., Aleti, T., Pallant, J., \&Zeleznikow, J. (2018). Helpful or harmful? Exploring the impact of social media usage on intimate relationships. Australasian Journal of Information Sy Clayton RB, Nagurney A, Smith JR. Cheating, Breakup, and Divorce: Is Facebook Use to Blame? Cyberpsychology, 